\title{
30. The Physical Nature of Interplanetary Dust as Inferred by Particles Collected at $35 \mathrm{~km}$
}

\author{
Donald E. Brownlee \\ PAUL W. HODGE \\ AND \\ William Bucher \\ University of Washington \\ Seattle, Washington
}

\begin{abstract}
Particles were collected at an altitude of $35 \mathrm{~km}$ by two flights of a volume-sampling micrometeorite collector. The collection scheme is very sensitive and is capable of collecting a significant number of particles. Many of the particles collected have chemical compositions similar to solar or to iron meteorites. Morphology of collected particles indicates that both true micrometeorites and ablation products were collected.
\end{abstract}

\begin{abstract}
A BaLloon-BORNe Micrometeorite COLLECTOR $A$ has been built which is sensitive enough to collect significant numbers of true micrometeorites even if the actual particle flux is an order of magnitude less than that indicated by penetration detectors mounted on spacecraft. Collections are made at $35-\mathrm{km}$ altitude, a level where under normal conditions the probability of finding terrestrial aerosols larger than $3 \mu$ is exceedingly small (Junge, 1961). The collector is a volumesampling device and is orders of magnitude more sensitive than other collection devices, primarily because it takes advantage of the tremendous spatial concentration of extraterrestrial dust particles in the stratosphere.
\end{abstract}

\section{COLLECTOR DESIGN}

The collector consists basically of an air pump which pulls air through an array of cylindrical collection rods. Particles are collected on the oilcoated rods by inertial deposition. The collection rods are 0.25 -in. diameter $\times 2.25$-in. long and are nearly 100 percent efficient for collecting particles (larger than $2 \mu$ ) from the $350-\mathrm{ft} \mathrm{s}^{-1}$ moving air stream. The design of the collector is shown schematically in figure 1 . The pump is an air ejector system similar in principle to the one described by Wood et al. (1966). The driving gas for the pump is derived from the catalytic decomposition of hydrazene. The collector's fuel tanks carry $150 \mathrm{lb}$ of hydrazene and the pump is capable of sampling over $10^{6} \mathrm{ft}^{3}$ of ambient air at $35 \mathrm{~km}$ during a 5-hr period. The pump draws air through the horn-shaped air inlet and the collection-rod assembly. The 22 collection rods are mounted normal to the air flow in a slide-gate mechanism that seals the collection rods from contamination before and after the collection phase of the flight. A cover over the end of the horn and a butterfly valve just behind the collection-rod assembly prevent contamination of the air channel upstream and downstream of the collection rods before collection. The rod-holding assembly and the interior portions of the butterfly valve and inlet horn are critically cleaned in our class- 100 cleanroom in Seattle, coated with silicone oil and sealed from 

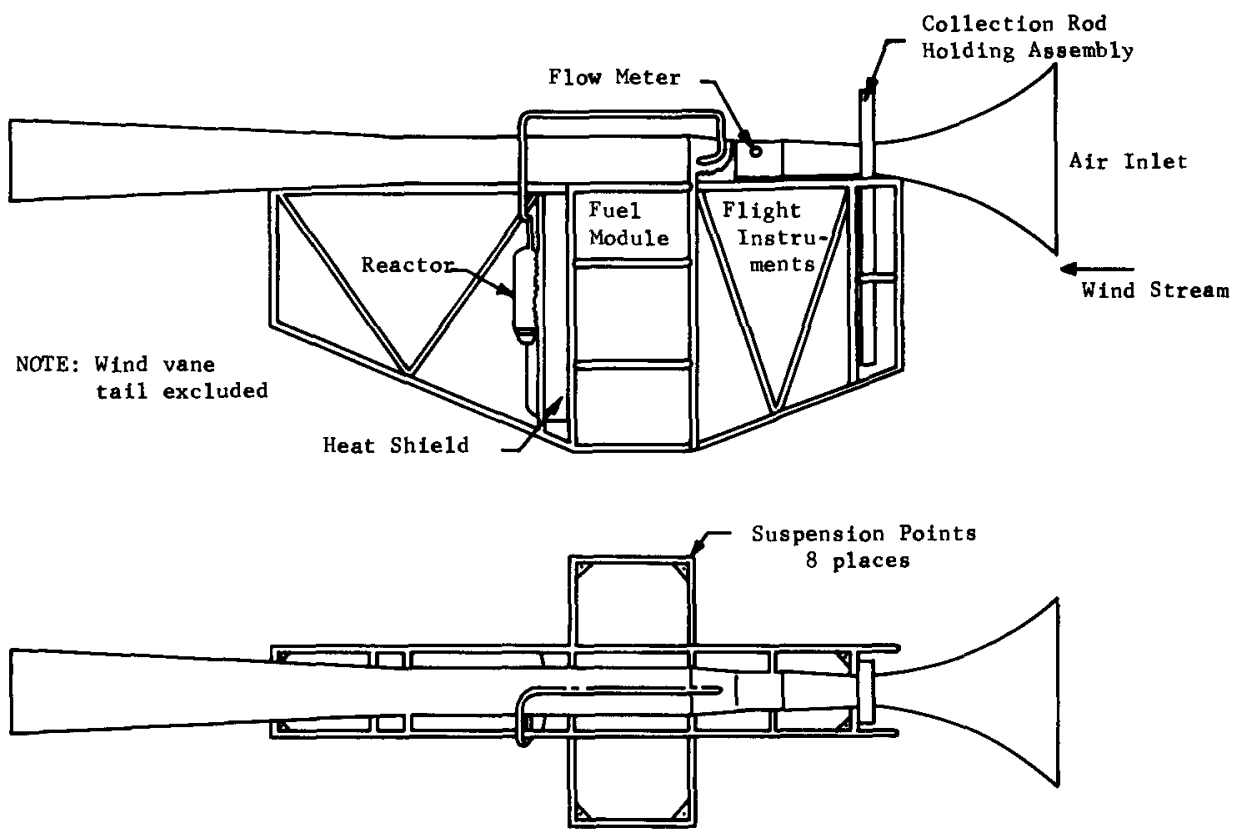

FIGURe 1.-Collector schematic diagram.

contamination until the collector begins to function $35 \mathrm{~km}$ over Texas.

To prevent contamination from the balloon, rigging, and exterior portions of the gondola, the collector is suspended $3000 \mathrm{ft}$ below the balloon on a nylon line. The wind-velocity gradient in the stratosphere typically produces a wind against the collector of $5 \mathrm{ft} \mathrm{s}^{-1}$. This wind completely isolates the collector from particulate matter emitted by the balloon and is used to isolate the collector's air inlet from dust generated by the gondola and pump exhaust. A 30-ft boom (see fig. 2) is attached to the exhaust end of the collector. At altitude, $400 \mathrm{ft}^{3}$ of sail area is deployed at the end of the tail which gives the collector the aerodynamic characteristics of a wind vane. The wind acting on the tail orients the gondola so that the air inlet horn is at all times upwind of all other parts of the system. The environment is exactly analogous to a laminar-flow cleanroom. The orientation of the collector is monitored both with a flux gate magnetometer and with a sequence camera.

Because of the orientation of the cylindrical collection rods relative to the airstream, particles can only be collected on one half of each rod. For each rod the upstream half is considered a collection surface and the downstream half is considered a

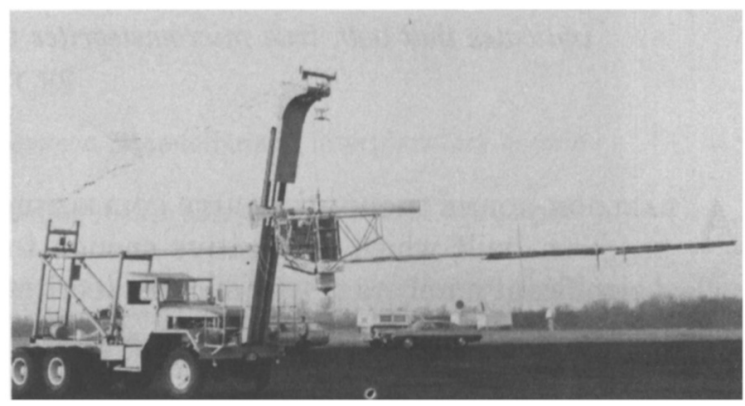

Figure 2.-Collector just prior to launch.

control. Both halves of each rod go through exactly the same cleaning and handling procedures so that the control technique is nearly ideal.

\section{COLLECTION FLIGHTS}

The collector, the Vacuum Monster (VM), has now had two collection flights, one on April 21, 1970 and one on May 2, 1971. The ambient-air volume actually sampled by the collection rods on the first and second flights was $171000 \mathrm{ft}^{3}$ and $200000 \mathrm{ft}^{3}$ respectively. On the first flight the microscopic rod scanning techniques were 100 percent effective for only particles $10 \mu$ and larger. 
On this flight 12 particles $(\geq 10 \mu)$ were found on the upwind sides of the collection rods and seven on the downwind sides. This is not a good signal-to-noise ratio but morphological analysis with a scanning electron microscope (SEM) and chemical analysis with a microprobe indicates that at least two of the particles are very probably extraterrestrial. One is a $12-\mu$ opaque spherule (fig. 3) and the other is a $10 \mu \times 30 \mu$ cellular particle (fig. 4). Microprobe analysis indicates that the major constituents of the sphere are $\mathrm{Fe}$ and $\mathrm{Mg}$ (Si could not be detected because of interference from the substrate) and the minor constituents are $\mathrm{Ni}, \mathrm{Ti}, \mathrm{Cr}$. The $\mathrm{Fe}$ content of the sphere is $\sim 15$ percent and the $\mathrm{Mg}$ content is roughly similar. The composition of the cellular particle is $\mathrm{Si}, \mathrm{Mg}, \mathrm{S}$, and $\mathrm{Fe}$ in order of abundance.

On the second collection flight, techniques were improved so that the scanning process was 100 percent efficient for particles $\geq 5 \mu$ and about 25 percent efficient for $3-\mu$ particles. The scanning process detected 306 particles $(\geq 3 \mu$ ) (fig. 5) on the upwind sides of the rods and none on the downstream sides. This is an excellent signal-to-noise ratio and indicates that all the particles on the rods came in through the horn during the collection phase of the flight. The largest particle collected was a $12-\mu$ transparent spherule with chondritic composition. The number of large particles collected on this flight is in agreement with the number on the first flight if one subtracts the background contamination. The size distribution of the second collection is very steep and most of the particles are $2 \mu$ to $3 \mu$ in size. Over 80 percent of all the particles collected are spheres. Ninety percent of the spheres are transparent. Of the irregular particles many are highly irregular with a very low density structure. Microprobe analysis of 50 of the particles indicates that a little over 10 percent of the collection has meteoritic composition. Most of the transparent spheres are aluminum oxide. It seems unlikely that these could be extraterrestrial and at this point we are not sure whether the transparent spheres came from the pump exhaust or the atmosphere. Neither source seems reasonable and at present the $\mathrm{Al}_{2} \mathrm{O}_{3}$ spheres are a real mystery. All of the nontransparent spheres analyzed to date have meteoritic compositions. Some are $\mathrm{Fe}, \mathrm{Ni}(\mathrm{Fe} / \mathrm{Ni} \approx 20)$ and others are $\mathrm{Fe}, \mathrm{Ni}, \mathrm{S}$. Of the irregular particles analyzed, few contained detectable elements. This is possibly due to the difficulty in microprobing small low-density particles. One of the irregular particles did, however, contain $\mathrm{Si}, \mathrm{Mg}, \mathrm{S}, \mathrm{Fe}$ and $\mathrm{Ni}$.
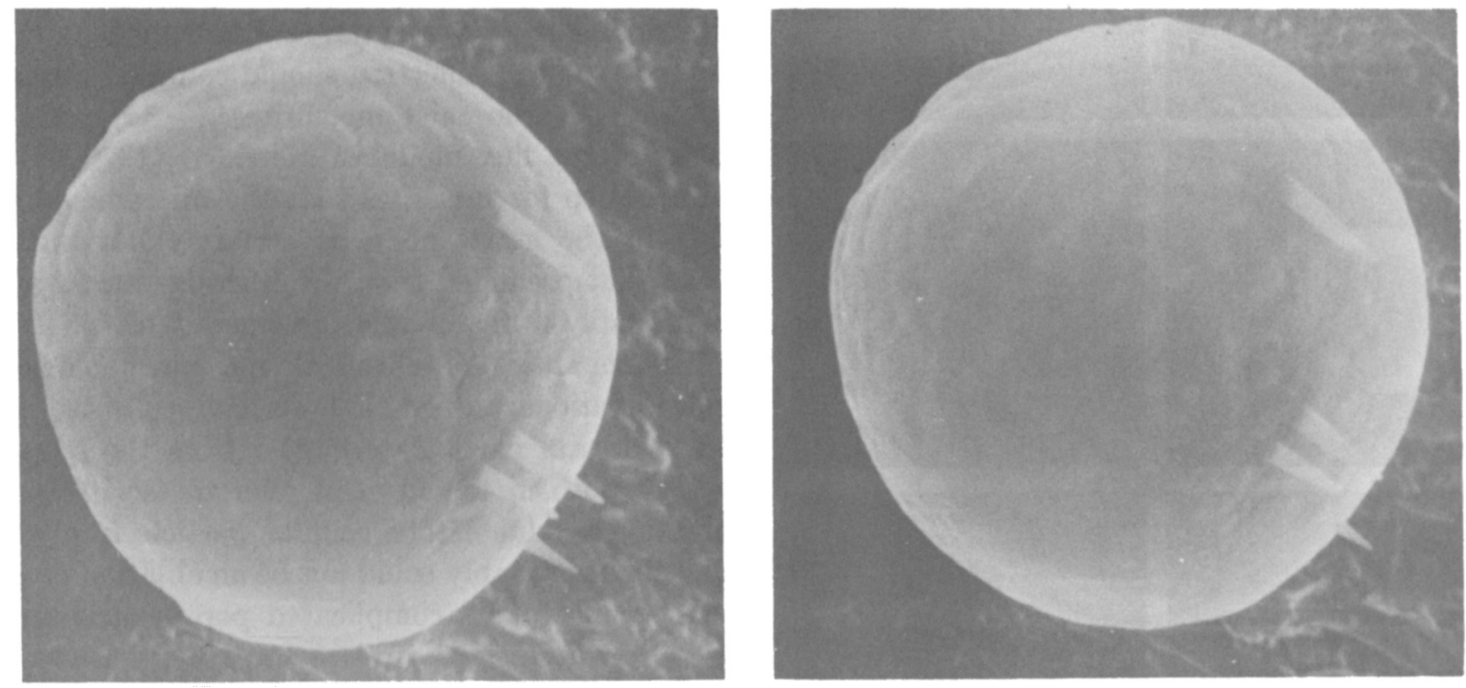

FIGURE 3.-A 12- $\mu$ spherule with chondritic composition. (A stereographic pair of photographs.) 


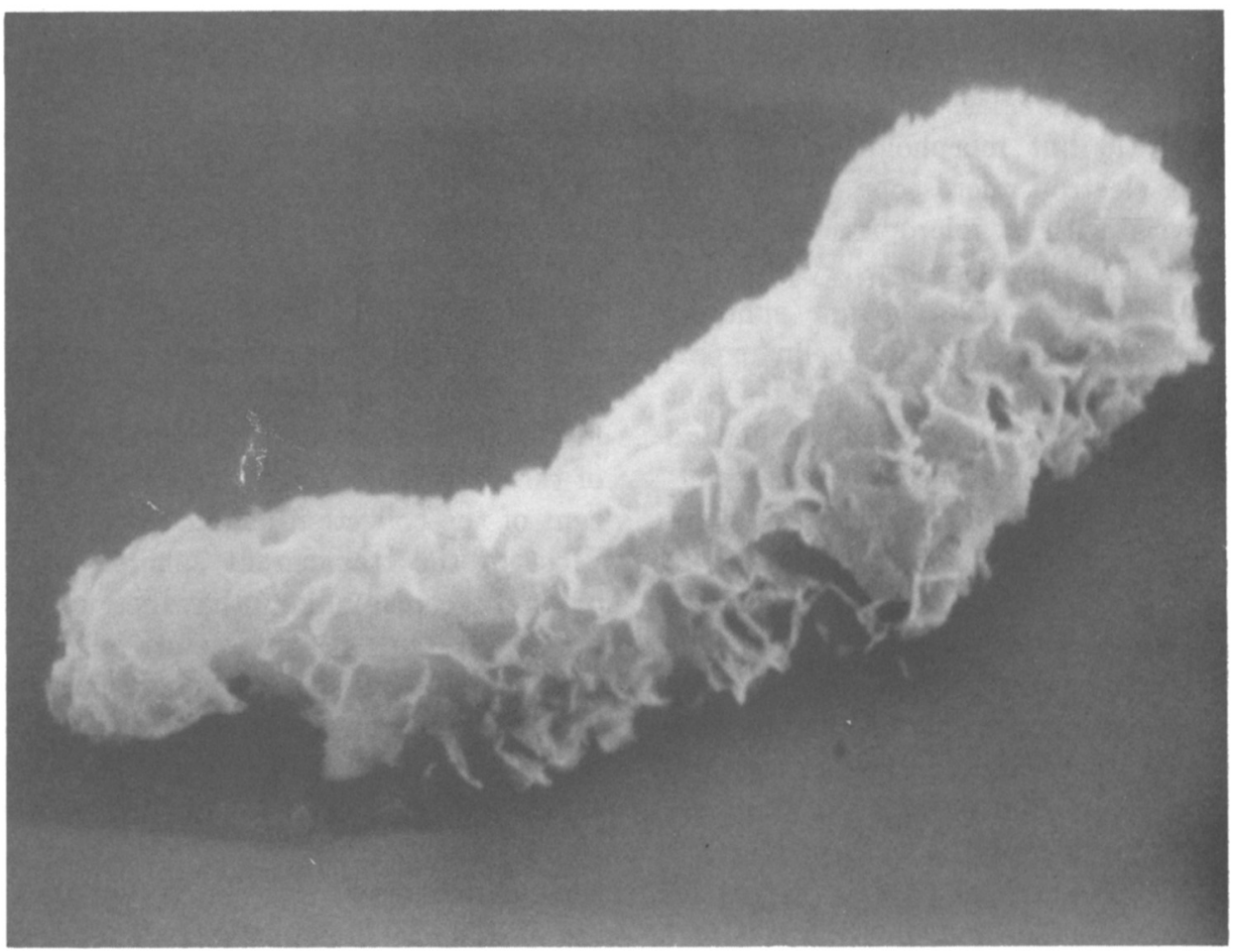

FigdRe 4.-A $30 \times 10 \mu$ cellular particle.
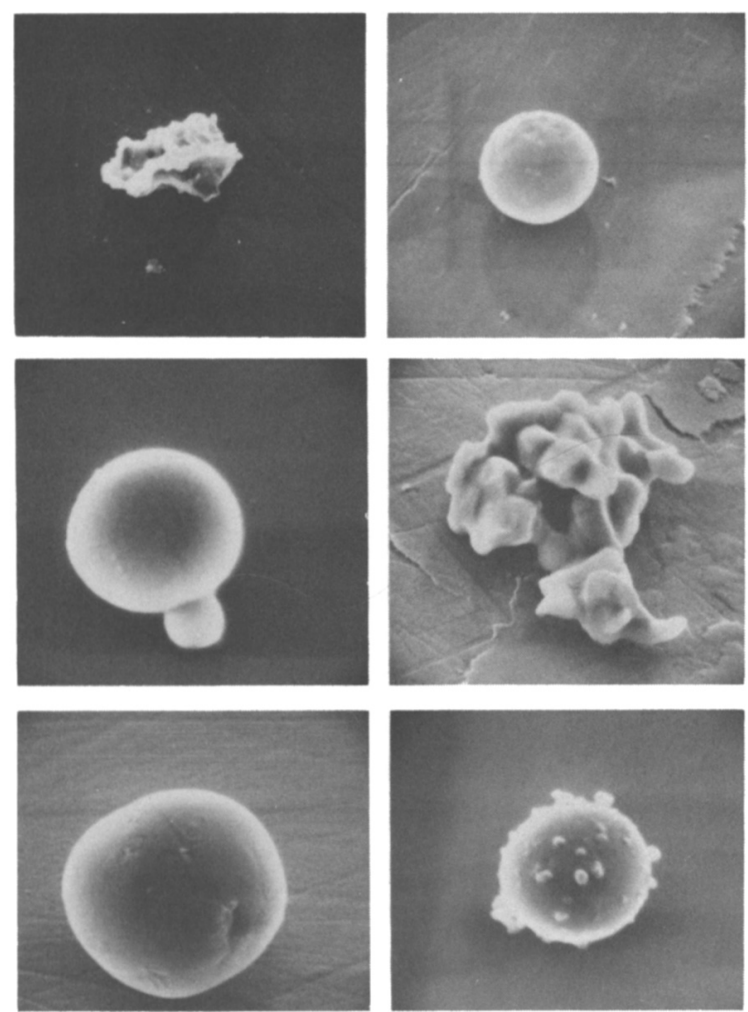

\section{CONCLUSION}

Both of the VM flights sampled large quantities of air and the time-area-products (TAP) of the collections is quite large. For the last flight the TAP for $3-\mu$ spheres (density $=3 \mathrm{~g} \mathrm{~cm}^{-3}$ ) was $7 \times$ $10^{5} \mathrm{~m}^{2} \mathrm{~s}$. This is a very large TAP and it is predicted that the collection should contain approximately 30 true micrometeorites $(\geq 3 \mu)$ on the basis of the flux model of Kerridge (1970). Our analysis so far indicates that the micrometeorite flux in the stratosphere is certainly not higher than that predicted from the Kerridge model and is probably in reasonable agreement with it.

On the basis of chemical and morphological considerations we feel that we have collected extraterrestrial particulate matter from the stratosphere both in the form of micrometeorites and ablation products. The cellular particle from the first flight probably could not be an ablation product because of its complicated porous structure.

Figure 5.-Particles of 3 to $4 \mu$ diameter from the second collection flight. 
The low-density structure and primitive nearsolar composition of this particle is strongly suggestive of a cometary origin. The spherule from the first flight has a similar composition to the cellular particle with the exception of the sulfur content. The sphere has an ordinary chondritic composition and we feel that it is most probably an ablation product of a larger body. Of the particles analyzed from the second flight most of those with meteoritic compositions are spheres and are probably also ablation products. Excluding the $\mathrm{Al}_{2} \mathrm{O}_{3}$ spheres, the spheres seem to fall into three compositional groups: chondritic, nickel-iron and nickel-iron-sulfur. The irregular particles that contain detectable elements have compositions compatible with carbonaceous chondrites.

We plan to do extensive quantitative analysis on the meteoritic particles from the balloon collections for accurate comparison with the compositions of the standard source of interplanetary matter, meteorites. At this point in the analysis it seems that the composition of most of the meteoritic particles is similar to the most primitive meteorite types. This is consistent with the studies of trace elements in the lunar soil by Ganapathy et al. (1970) that indicate that the mean composition of micrometeorites is similar to that of the Type I carbonaceous chondrite meteorites. The structure of some of the irregular particles is very low density which is consistent both with comet models and meteor studies. The structure and compositions of these particles will be studied with the goal of determining the physical nature, origin, and space density of interplanetary dust grains.

\section{ACKNOWLEDGMENT}

We gratefully acknowledge the partial support of the National Aeronautics and Space Administration through Grant NGR 48-002-033.

\section{REFERENCES}

Ganapathy, R., Reid, R., Keays, J., Laul, J., And Anders, E., 1970. Trace elements in Apollo 11 lunar rocks: Implications for meteorite influx and origin of moon, Proc. A pollo 11 Lunar Sci. Conf., Geochim. Cosmochim. Acta, Suppl., 1, 1117-1142.

Junge, C. E., 1961. Stratospheric aerosol studies, J. Geophys. Res., 66, 2163-2182.

Kerridge, J. F., 1970. Micrometeorite environment at the Earth's orbit, Nature, 288, 616-619.

Wood, R., Zeller, H., Olson, R., Deeter, R., Maffitt, K., ANd Anderson, H., 1966. Studies of extraterrestrial dust at 40 km, Applied Sci. Div., Litton Systems, Inc., Rept. No. 3063. 